\title{
Synthesis and Characterization of Aminophosphonates Zirconium as New Mesoporous Materials
}

\author{
LIANG ZHOU
}

College of Chemistry and Chemical Engineering, Southwest University, Chongqing 400715, P.R. China

cosa007cosa007@126.com

Received 13 November 2011; Accepted 15 January 2012

\begin{abstract}
A serial of aminophosphonates zirconium with the different arm lengths of $-\left(\mathrm{CH}_{2}\right) n$ - organic chains $(\mathrm{n}=2-6)$ was synthesized for the first time. These compounds are characterized by FT-IR, SEM, TEM, TG and nitrogen adsorption-desorption. And based on the experimental data, these materials not only have layer structure mesoporous and good thermal stability such as zirconium phosphate, but also can be adjusted the layer distance, pore size and pore volume. So aminophosphonates zirconium posses special excellent properties and will have potential prospect applications.
\end{abstract}

Keywords: Mesoporous materials; Aminophosphonates Zirconium; Synthesis and Characterization.

\section{Introduction}

Zirconium phosphonate and its derivatives are very important compounds to use in the field of catalysis, adsorption, ion exchange and/or functional materials. If the $\mathrm{P}-\mathrm{OH}$ bonds in the molecule of zirconium phosphonate are whole or part changed to the $\mathrm{P}-\mathrm{R}$, the compounds become organic zirconium phosphonates or their derivatives ${ }^{[1-3]}$. The common inorganic materials such as mesoporous, macroporous silica gel and molecular sieve with surface of single hydroxyl have difficult to be further modified ${ }^{[4-6]}$. A variety of functional groups of 
zirconium phosphonates can overcome this problem. By controlling the synthesis conditions, zirconium phosphonates with different groups and spacing of layers can be prepared. Zirconium phosphonates as supports in catalysis have recently been highlighted as a new option for the immobilization of homogeneous catalysts ${ }^{[7-8]}$.

They generally have amorphous structure with high specific surface area that let reactive sites fully expanded. And the container effects of micropores and mesopores of zirconium phosphonates are benefit to chemical reaction sufficient occurring.

In this paper, a serial of aminophosphonates zirconium with the different arm lengths of $-\left(\mathrm{CH}_{2}\right) \mathrm{n}$ - organic chains ( $\left.\mathrm{n}=2-6\right)$ was synthesized for the first time. These compounds are characterized by FT-IR, SEM, TEM, TG and nitrogen adsorption-desorption.

\section{Experimental}

\section{Material and Methods:}

FT-IR spectra were recorded on Bruker RFS100/S spectrophotometer (USA) using $\mathrm{KBr}$ pellets in the $400-4000 \mathrm{~cm}^{-1}$ range. ${ }^{1} \mathrm{H},{ }^{13} \mathrm{C}$ and ${ }^{31} \mathrm{P}$ NMR spectra were recorded by using an av-300 NMR instrument at 300, 75 and $121 \mathrm{MHz}$, respectively. TG analyses were performed on a SBTQ600 Thermal Analyzer (USA) with the heating rate of $20^{\circ} \mathrm{C} / \mathrm{min}$ in the temperature range of $30-1200^{\circ} \mathrm{C}$ under flowing $\mathrm{N}_{2}(100 \mathrm{~mL} / \mathrm{min}) . \mathrm{N}_{2}$ adsorption-desorption isotherms carried out at $77 \mathrm{~K}$ on Autosorb-1 apparatus (Quantachrome). The surface areas were determined by using the BET equation, and the average pore size was estimated according to the BJH model. Scanning electron microscopy (SEM) analysis was performed on S-4800 FE-SEM instrument (Hitachi). Transmission electron microscopy (TEM) analysis was recoded on a TECNAI10 (PHILIPS, Holland) apparatus.

Phthalimide was purchased from Alfa Aesar. Other commercially available chemicals were laboratory-grade reagents from local suppliers.

Synthesis of Aminophosphonates Zirconium:

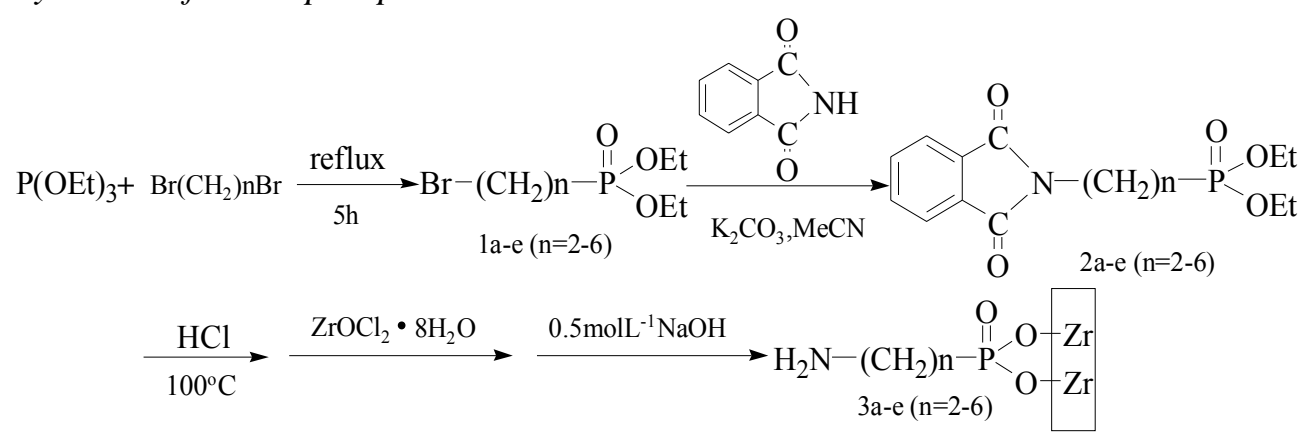

Figure 1. The synthese route of aminophosphonates zirconium.

(1) In the dried three-necked flask $(250 \mathrm{~mL})$ was charged $\omega$-alkane dibromide $(\mathrm{n}=2-6)$ $(237 \mathrm{mmol})$ and followed by dropwise addition of triethyl phosphate $(13.11 \mathrm{~g}, 79 \mathrm{mmol})$ 
refluxed for $5 \mathrm{~h}$ with the tracking of TLC. The reaction mixture was chromatographed on a silica gel column eluted with petroleum ether $\left(60-90^{\circ} \mathrm{C}\right) /$ ethyl acetate $(10: 1$ in volume $)$ to give $1 \mathrm{a}-\mathrm{e}^{[10]}$, respectively in $75-85 \%$ yield.

(2) In the dried three-necked flask $(250 \mathrm{~mL})$ was charged anhydrous $\mathrm{K}_{2} \mathrm{CO}_{3}(5.5 \mathrm{~g}, 40$ $\mathrm{mmol})$ and phthalimide $(5.88 \mathrm{~g}, 40 \mathrm{mmol})$, flushed three times with nitrogen at room temperature, added dropwise $100 \mathrm{~mL}$ acetonitrile solution of $1 \mathrm{a}-\mathrm{e}(\mathrm{n}=2-6)(40 \mathrm{mmol})$ then refluxed for $48 \mathrm{~h}$ with the tracking of TLC. The reaction mixture was concentrated under reduced pressure. After removal of the solvent, the residue was diluted with $\mathrm{CHCl}_{3}(100 \mathrm{~mL})$ and then was washed with brine $(30 \mathrm{~mL} \times 3)$, dried over anhydrous $\mathrm{Na}_{2} \mathrm{SO}_{4}$ and concentrated under reduced pressure to give the pale yellow liquid. The crude product was purified by silica gel column chromatography using petroleum ether $\left(60-90^{\circ} \mathrm{C}\right) / \mathrm{CHCl}_{3}(4: 1$ in volume) to give $2 \mathrm{a}-\mathrm{e}$, respectively in $58-64 \%$ yield.

(3) A mixture of $2 \mathrm{a}-\mathrm{e}(\mathrm{n}=2-6)(2 \mathrm{mmol}), 15 \mathrm{~mL}$ of hydrochloric acid $(36 \%)$ was stirred at $100^{\circ} \mathrm{C}$ for $24 \mathrm{~h}$ and concentrated under reduced pressure. Zirconium oxychloride $(1.7 \mathrm{~g}, 6$ $\mathrm{mmol}$ ) in $15 \mathrm{~mL}$ of deionized water was added dropwise and stirred at room temperature for another $16 \mathrm{~h}$. The white solid was filtered, dispersed in $50 \mathrm{~mL}$ of water, adjusted to $\mathrm{pH}=6-7$ by using sodium carbonate $(0.5 \mathrm{~mol} / \mathrm{L})$ and filtered again. The mud cake was washed with deionized water till chloride ion was not detected by using ion chromatography, and then dried at $60^{\circ} \mathrm{C}$ for $24 \mathrm{~h}$ under reduced pressure to afford aminophosphonates zirconium 3a-e, respectively in $52-63 \%$ yield.

\section{Results and Discussion}

\section{Infrared Spectroscopy:}

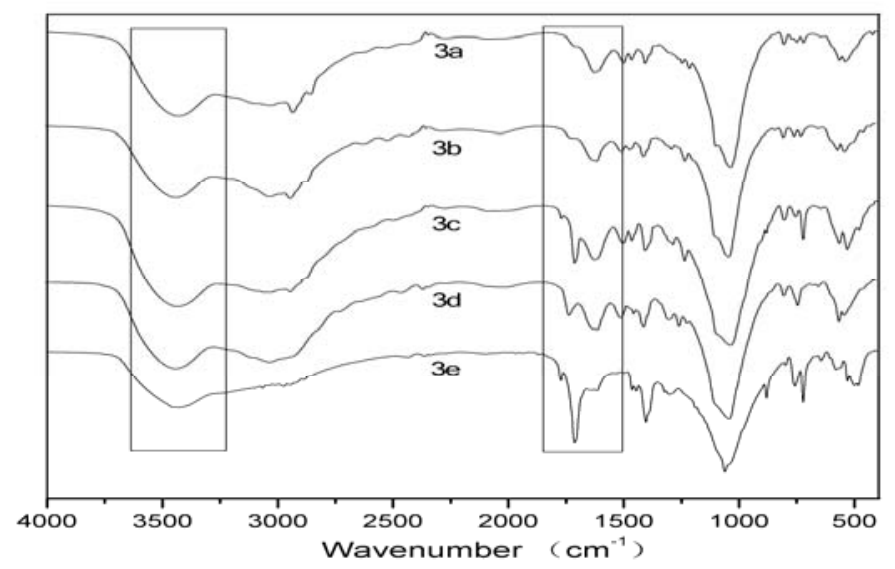

Figure 2. IR spectra of 3a-e.

The FT-IR spectra of the parent supports $3 \mathrm{a}-\mathrm{e}$ had the similar infrared spectroscopy in the $4000-500 \mathrm{~cm}^{-1}$ range. The $3 \mathrm{a}-\mathrm{e}$ exhibited bands at $3600-3200 \mathrm{~cm}^{-1}$ assigned to the 
characteristic vibration of the $-\mathrm{NH}$ groups. The several absorption peaks in the scan range $1686-1650 \mathrm{~cm}^{-1}$ for $3 \mathrm{a}-\mathrm{e}$ were attributed to the $\mathrm{N}-\mathrm{H}$ vibrations of the appended organic moieties. Therefore, based on IR spectra of 3a-e, it was demonstrated that aminophosphonates zirconium were successfully prepared.

\section{Surface Morphology:}

Scanning electron micrograph (SEM) was recorded to understand morphology of the surface of aminophosphonates zirconium in solid state. From the SEM images shown in Fig. 3 (a), 3a were conglomerated with the globular aggregates with the diameters of about 0.1-0.2 um, which indicated that the diameter of the particles of the material was in submicron. Also, it showed that the material was loose, and had various caves, holes and porous. Interestingly, $3 \mathrm{a}$ in the organic solvents were easily swollen, which could be verified by the TEM images. After the samples $4 \mathrm{a}-\mathrm{e}$ were dispersed in cyclohexane and stirred for $2 \mathrm{~h}$, their morphologies of the filiform structure with thickness about 20-50 nm and length about several micrometers was observed in Fig. 3(b). The similar SEM and TEM images and results were obtained for the other four compounds $3 \mathrm{~b}-\mathrm{e}$.
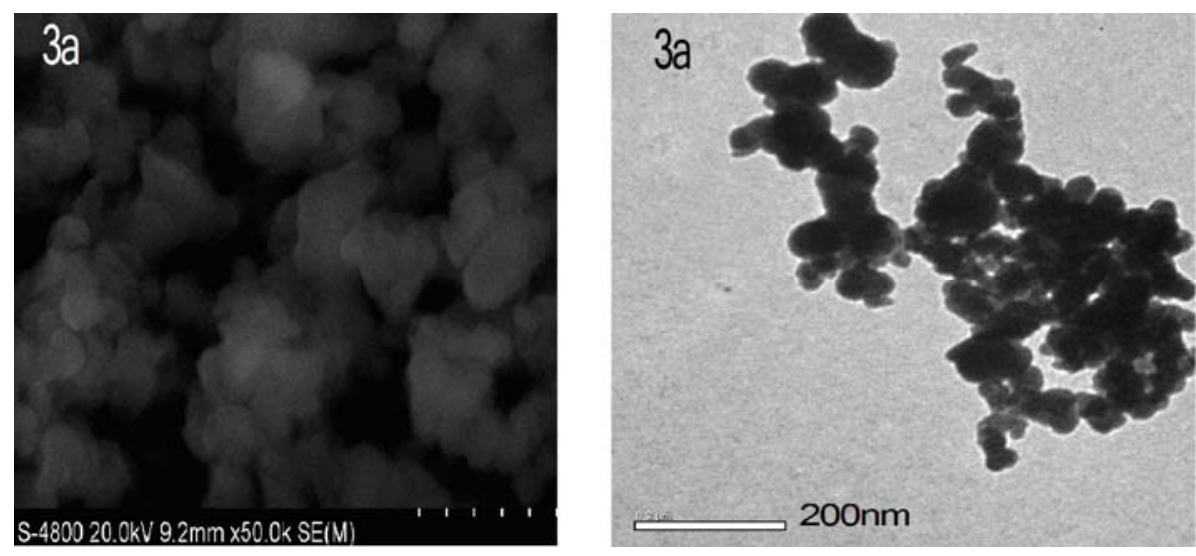

Figure 3. (a) SEM image of aminophosphonates zirconium 3a and (b) TEM image of aminophosphonates zirconium $3 \mathrm{a}$.

\section{Thermal Gravimetric Analysis:}

On heating the samples of aminophosphonates zirconium $3 \mathrm{a}$, the thermolysis over a broad temperature range of $40-1200^{\circ} \mathrm{C}$ with three steps of weight loss were observed (Fig. 4). The first slope curve was due to the desorption of the surface-bound or intercalated water from the pore channels at $50-100^{\circ} \mathrm{C}$. In the $100-200^{\circ} \mathrm{C}$, the thermal gravimetric curve is relatively flat. The sharp weight loss in the temperature range of $200-500^{\circ} \mathrm{C}$, accompanied by endothermic peaks in the DSC curves at $250^{\circ} \mathrm{C}$, corresponded to the decomposition of the 
appended organic fragments. Finally, in the temperature range of $600-1200^{\circ} \mathrm{C}$, the third slope curve was attributed to the dehydrolysis of $\mathrm{Zr}\left(\mathrm{HPO}_{4}\right)_{2}$ to $\mathrm{ZrP}_{2} \mathrm{O}_{7}$. The similar thermal gravimetric curves and results were obtained for the other four compounds $3 \mathrm{~b}-\mathrm{e}$.

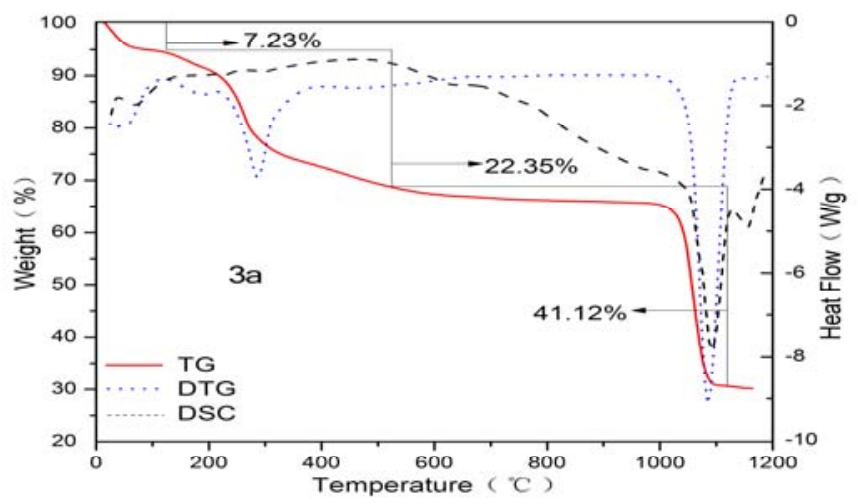

Figure 4. The thermal gravimetric curves of $3 \mathrm{a}$.

\section{Nitrogen Adsorption-Desorption Isotherms:}

The materials 3a-e all have the similar nitrogen adsorption-desorption isotherms (Fig. 5). The textural parameters of $3 \mathrm{a}-\mathrm{e}$ calculated by $\mathrm{N}_{2}$ adsorption and desorption isotherms at $77 \mathrm{~K}$ were presented in Table 1 . As expected, it was shown that $4 \mathrm{a}-\mathrm{e}(\mathrm{n}=2-6)$ were porous solid materials with the surface areas of $22.12-88.98 \mathrm{~m}^{2} / \mathrm{g}$, pore volumes of $0.072-0.445 \mathrm{cc} / \mathrm{g}$ and average pore sizes of 13.95-99.49 $\AA$. With the increase in arm chain lengths $n$ from 2 to 6 , it was observed that the surface areas of $3 \mathrm{a}-\mathrm{e}$ increased and average pore sizes decreased respectively.

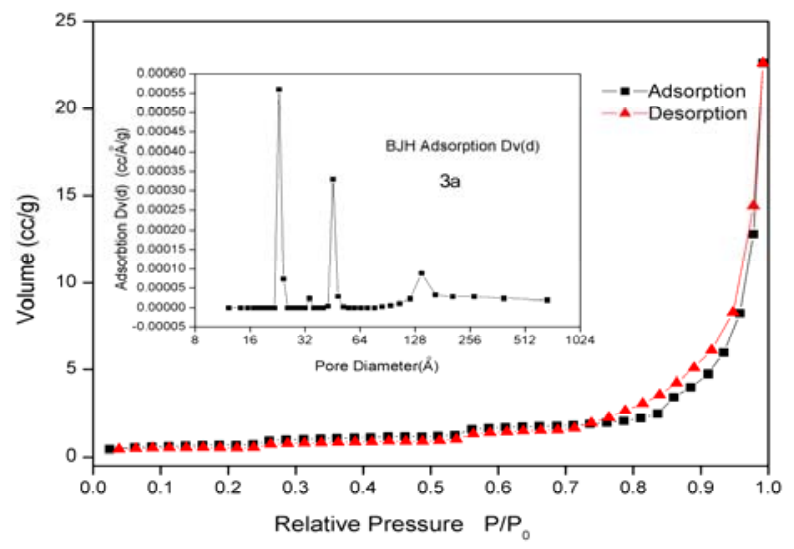

Figure 5. The nitrogen adsorption-desorption isotherms of $3 a$. 
Table 1. The surface area, pore diameter and pore volume of 3a-e.

\begin{tabular}{|c|c|c|c|}
\hline Samples $^{[\mathrm{a}]}$ & $\mathrm{S}_{\mathrm{BET}}\left(\mathrm{m}^{2} / \mathrm{g}\right)^{[\mathrm{b}]}$ & Pore Size $(\AA)^{[\mathrm{c}]}$ & Pore Volume $[\mathrm{cc} / \mathrm{g}]^{[\mathrm{d}]}$ \\
\hline $3 \mathrm{a}$ & 22.12 & 99.49 & 0.445 \\
\hline $3 \mathrm{~b}$ & 48.57 & 40.08 & 0.147 \\
\hline $3 \mathrm{c}$ & 53.44 & 25.61 & 0.095 \\
\hline $3 \mathrm{~d}$ & 73.31 & 21.73 & 0.089 \\
\hline 3e & 88.98 & 13.95 & 0.072 \\
\hline
\end{tabular}

A reasonable and plausible explanation of this change in surface area and average pore size was that the longer arm chain lengths $\mathrm{n}$ from 2 to 6 made the inorganic zirconium layers more expanded and amorphous, and then the more surface areas were obtained. In the other hand, the organic moieties with the arm chain lengths $n$ from 2 to 6 between the neighbor zirconium layers tended to be more close packing in the interlayer region, which caused the less free pores and the decrease in the average pore sizes from 99.49 to $13.95 \AA$.

\section{Conclusions}

In summary, the materials of aminophosphonates zirconium were successfully prepared for the first time. Owing to their layered mesoporous structures, these aminophosphonates zirconium could act as catalyst supports, enabling one to take advantage of the rigid frame, the confinement effect and the cooperation effect, and bridging the gap between heterogeneous catalysts and homogeneous catalysts.

\section{Acknowledgments}

Author is grateful to Southwest University of China for financial support.

\section{References}

1. Clearfield A.; Blessing R. H.; Stynes J. A. [J]. J. Inorg. Nucl. Chem., 1968, 30: 2249-2258.

2. Troup J. M.; Clearfield A. [J]. Inorg. Chem., 1977, 16: 3311-3314.

3. Poojary D. M.; Shpeizer B. G.; Clearfield A. [J]. J. Chem. Soc. Dalton Trans., 1995, 1: 111-113. 
1326 Liang Zhou

4. Clearfield A.; Wang Z. [J]. J. Chem. Soc. Dalton Trans., 2002, 15: 2937-2947.

5. Ma X B.; Fu X K. [J]. J. Mol. Catal. A: Chem., 2003, 195: 47-53.

6. Ma X B.; Fu X K. [J]. J. Mol. Catal. A: Chem., 2004, 208: 129-133.

7. Pugin B.; Landert H.; Spindler F.; Blaser H. U. [J]. Adv. Synth. Catal., 2002, 344: 974-979.

8. Ma X B.; Liu J.; et al. [J]. J. Mater. Chem., 2009, 19: 1098-1104

9. Bhattacharya A. K.; Thyagarajan G. [J]. Chem. Rev., 1981, 81: 415-430.

10. Xu Z.; Ma X B.; et al. [J]. Catal. Commun., 2009, 10: 1261-1266 and the references cited therein. 


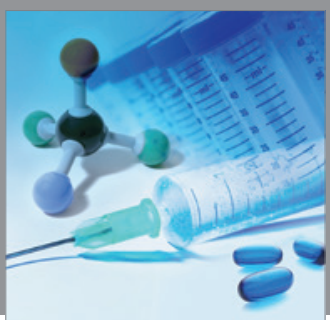

International Journal of

Medicinal Chemistry

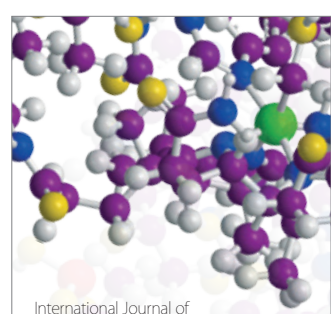

Carbohydrate Chemistry

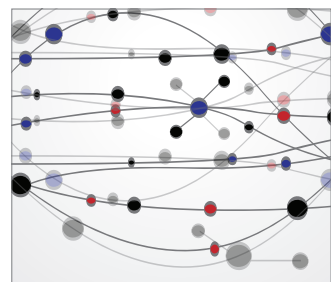

The Scientific World Journal
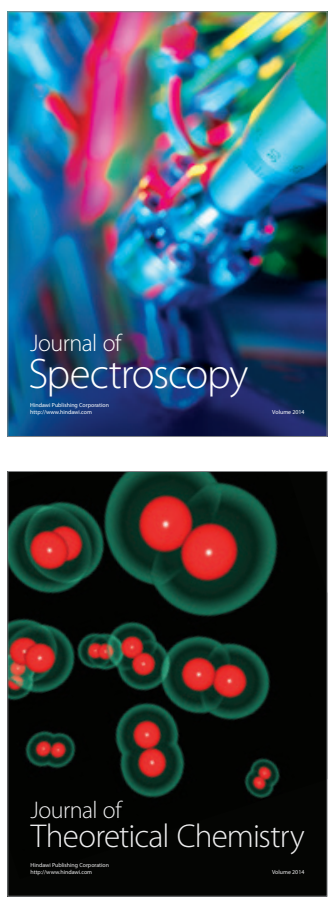
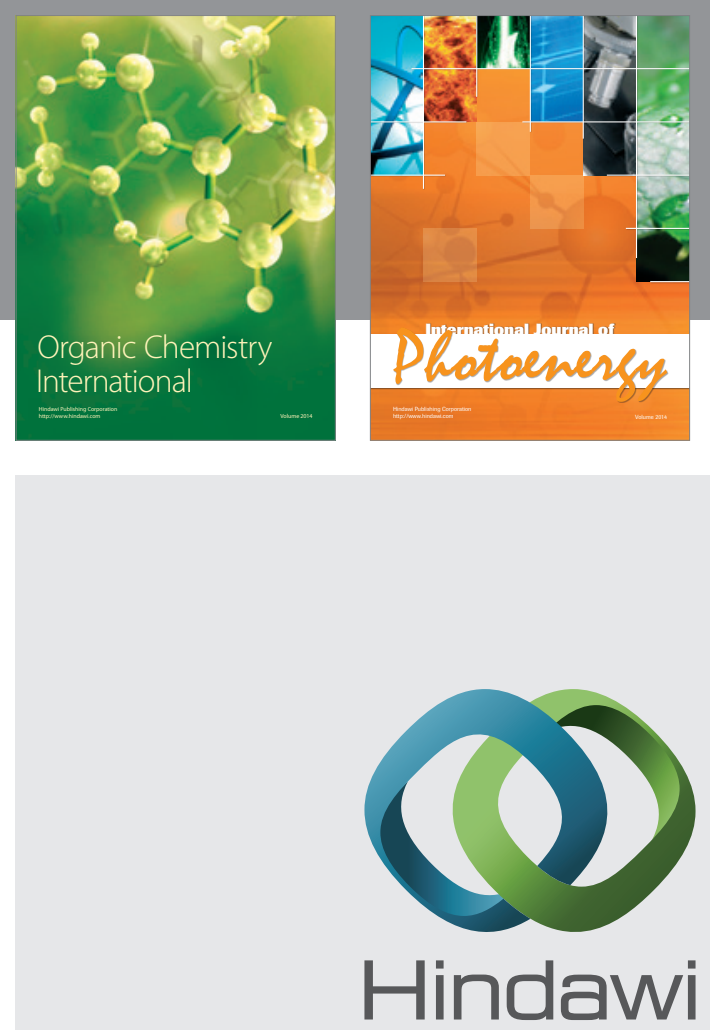

Submit your manuscripts at

http://www.hindawi.com
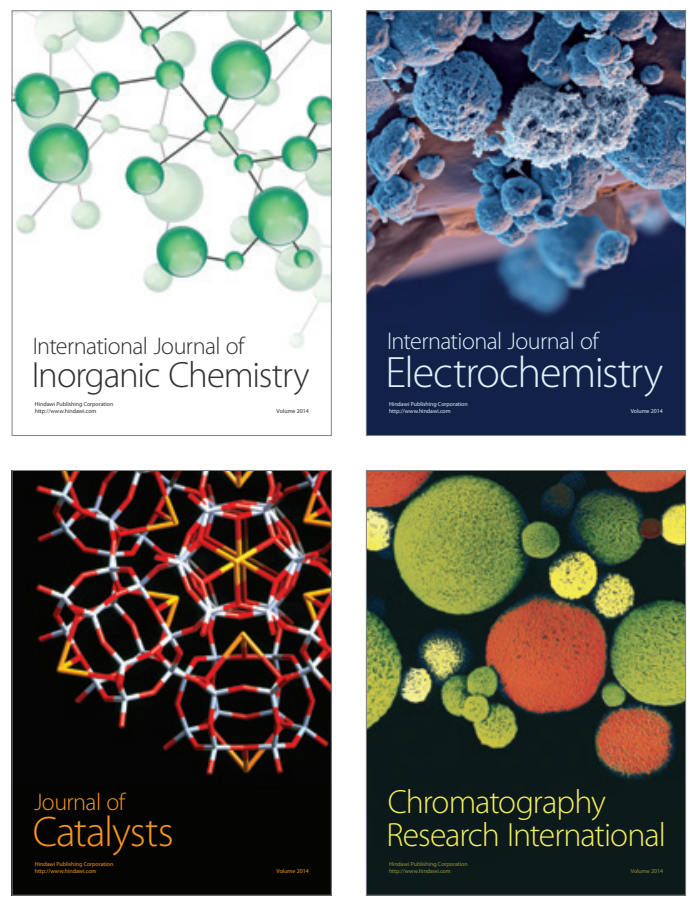
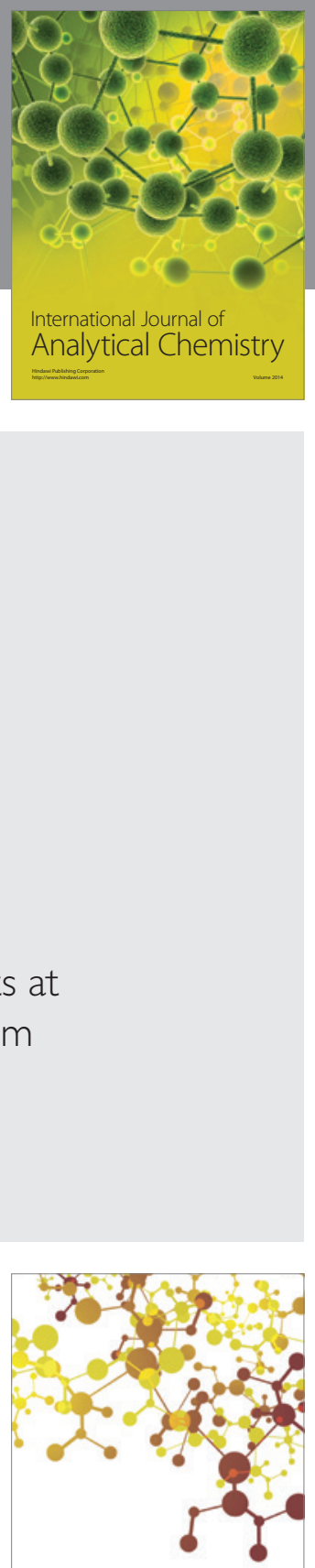

Journal of

Applied Chemistry
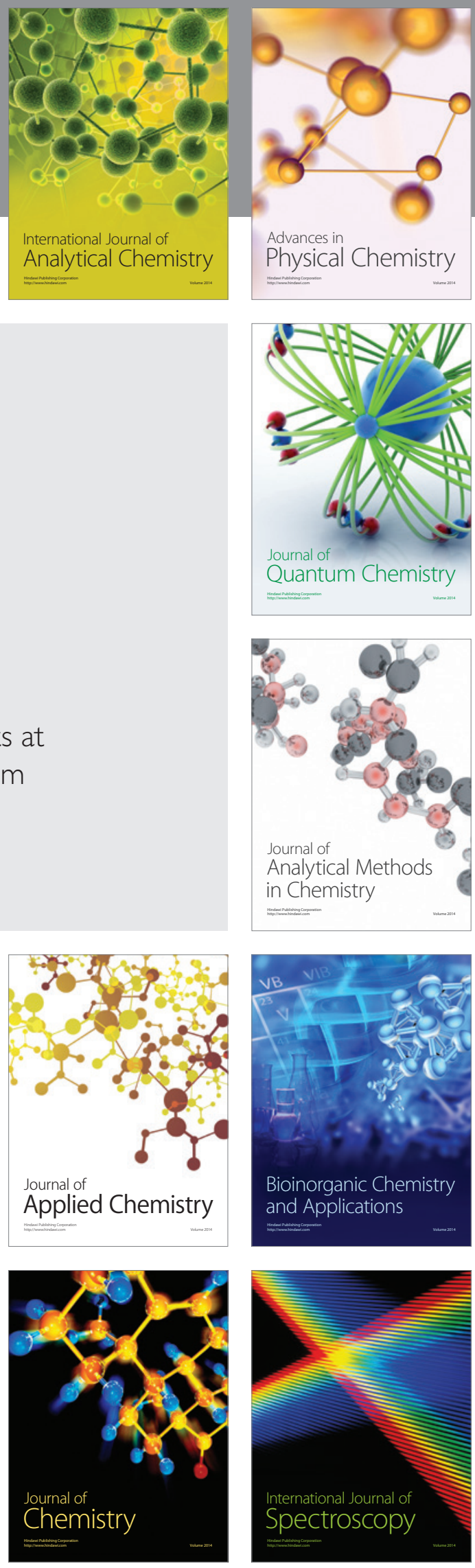